\title{
Research on the Crowdfunding Problems Affecting Small and Micro Enterprises \\ Qi Wu
}

Xi'an University, NO1,Keji six Road, Yanta District of Xi'an, China,710065

13991381515@163.com

Keywords: Financing; Crowdfunding; Platform; Regulation

\begin{abstract}
The financial issue has always been the main bottleneck restricting the healthy development of small and micro enterprises. Crowdfunding makes full use of the characteristics of the Internet that is fast, open, and flexible. It can quickly and efficiently solve the financing problems of small and micro enterprises and promote economic growth. However, as a crowdfunding financing model is still being explored in our country, the theoretical system is still not perfect. Therefore, studying the status quo and problems of the crowdfunding financing model and improving the crowdfunding financing model laws and technology platforms have a very important positive significance in breaking through the financing plight of small and micro enterprises, accelerating the speed of the development of small and micro enterprises, and promoting the development of China's national economy.
\end{abstract}

\section{影响小微企业众筹融资问题研究}

\author{
吴琦 \\ 西安文理学院经济管理学院, 雁塔, 西安, 陕西, 中国
}

13991381515@163.com

关键词：融资；众筹；平台；监管

中文摘要. 资金问题始终是制约小微企业健康发展的主要瓶颈。众筹融资充分利用了互联网快 速、开放、灵活的特点, 能够快速高效地解决小微企业融资问题, 推动经济增长。然而, 作 为众筹融资模式在我国还处于探索中, 理论体系尚不完善。所以, 研究众筹融资模式现状和 问题, 完善众筹融资模式法律和技术平台, 对突破小微企业众筹融资困境, 加快小微企业发 展速度, 带动我国国民经济发展有着十分重要的积极意义。

\section{1. 众筹的概念}

众筹，出自英文单词 Crowdfunding，被译为大众筹资或者群众筹资，利用团购+预购的 方法, 面向大众集资的一种新模式, 发起人利用互联网和 SNS, 将有创意、可操作的项目或 活动, 展示在众筹平台上, 获取大家的关注, 感兴趣的投资者对其提供资金支持, 项目成功 后给予投资者相应回报。发起人（筹资人）、平台（中介机构）和投资者构成了众筹的三要 素。其中, 发起者在众筹平台上展示将要筹资的项目, 通过文字、图片、视频等新式介绍产 品或创意并设定筹款期限、模式、额度和预期回报率等内容。平台即众筹网站, 是连接发起 者和投资者之间的桥梁（媒介）。平台则对众筹项目的估值、信息披露、融资金额合理性等 情况进行严格审核，通过者予以筹资。投资人则通过浏览平台上的各类项目，挑选适合的、 感兴趣的项目进行投资。 


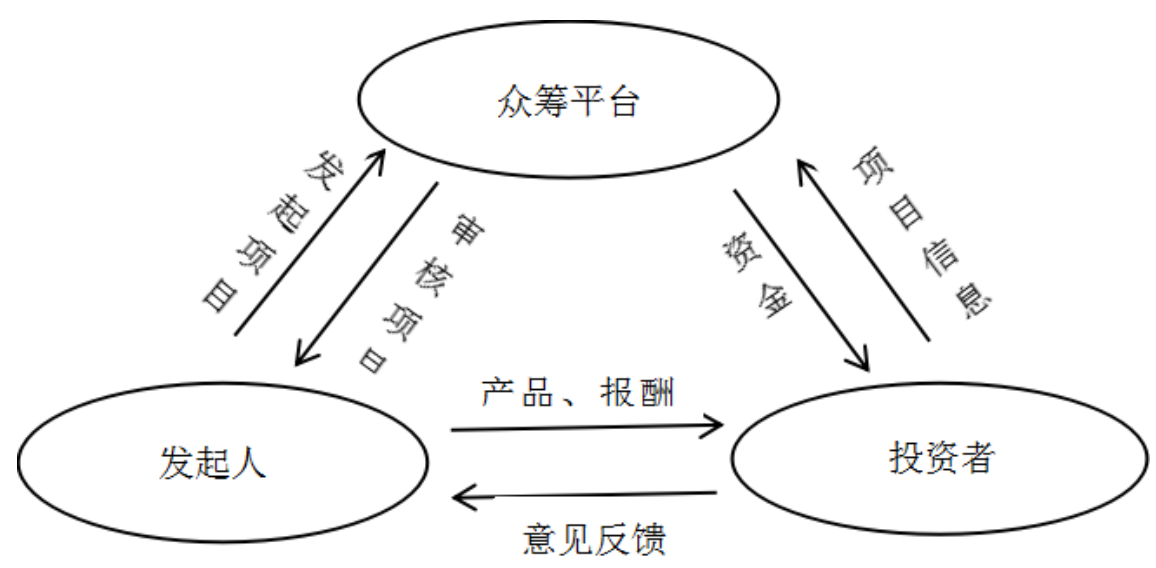

图 1 众筹融资模式

\section{2. 众筹的模式}

根据 Massolution 在 2012 年 “众筹行业报告” 里的描述, 可以将众筹融资分为股权、债 券、回报（产品）和公益（捐赠）众筹四种类型，具体介绍见下表。

表 2 众筹模式

\begin{tabular}{|c|c|c|c|c|}
\hline 众筹模式 & 股权众筹 & 债券众筹 & 回报众筹 & 公益众筹 \\
\hline 含义 & $\begin{array}{l}\text { 是指公司出让一定比例 } \\
\text { 的股权, 投资者对众筹项 } \\
\text { 目或公司投资, } \\
\text { 获得未来收益. }\end{array}$ & $\begin{array}{l}\text { 投资者对项目或 } \\
\text { 公司进行投资, 获 } \\
\text { 得一定比例债权, } \\
\text { 在未来获取收益 } \\
\text { 并收回本金 }\end{array}$ & $\begin{array}{l}\text { 指投资人对项目出 } \\
\text { 资, 用以开发该种产 } \\
\text { 品 (或服务), 待其 } \\
\text { 开始对外销售或已 } \\
\text { 具备销售条件时, 投 } \\
\text { 资者获得产品或服 } \\
\text { 务 }\end{array}$ & $\begin{array}{l}\text { 指通过众筹平台发 } \\
\text { 布众筹项目, 投资者 } \\
\text { 进行无偿出资的公 } \\
\text { 益行为 }\end{array}$ \\
\hline $\begin{array}{c}\text { 代表性众筹 } \\
\text { 平台 }\end{array}$ & 天使汇 & 人人贷 & 众筹网 & 微公益 \\
\hline 简介 & $\begin{array}{l}\text { 成立于 } 2011 \text { 年 } 11 \text { 月, 国 } \\
\text { 内首家发天使投资人众 } \\
\text { 筹规则的中小企业众筹 } \\
\text { 平台。截至 } 2013 \text { 年 } 10 \\
\text { 月, 共完成 } 70 \text { 个项目, } 2 \text {. } \\
5 \text { 亿人的融。在该 } \\
\text { 平台注册的创业项目达 } \\
\text { 到 } 8000 \text { 个, 通过审核挂 } \\
\text { 牌的企业超过 } 1000 \text { 家, } \\
\text { 创业者会员超过 } 22000 \\
\text { 位。 }\end{array}$ & $\begin{array}{l}2010 \text { 年 } 5 \text { 月成立, } \\
\text { 指有资金并且有 } \\
\text { 理财投资想法的 } \\
\text { 个人, 通过第三方 } \\
\text { 网络平台牵线搭 } \\
\text { 桥的平台。截至 } 2 \\
015 \text { 年 } 9 \text { 月中旬, } \\
\text { 人人贷平台总交 } \\
\text { 易额达到 } 108 \text { 亿。 }\end{array}$ & $\begin{array}{l}2013 \text { 年 } 2 \text { 月正式上 } \\
\text { 线, 是中国最具影响 } \\
\text { 力的众筹平台。提供 } \\
\text { 包括智能硬件、娱乐 } \\
\text { 演艺、影视图书、公 } \\
\text { 益服务等 } 10 \text { 大频 } \\
\text { 道, } 4000 \text { 多个项目, } \\
\text { 众筹项目最多, 众筹 } \\
\text { 金额最高。 }\end{array}$ & $\begin{array}{l}\text { 该平台 } 2012 \text { 年 } 2 \text { 月 } \\
\text { 上线, 主要有: 个人 } \\
\text { 求助、转发捐助、微 } \\
\text { 拍卖等三款产品 }\end{array}$ \\
\hline 代表案例 & $\begin{array}{c}\text { 嘀嘀打车、 } \\
\text { 黄太吉传统美食 }\end{array}$ & 薪计划、U 计划 & $\begin{array}{c}\text { 设立"众筹大学"、那 } \\
\text { 英演唱会 }\end{array}$ & $\begin{array}{c}\text { 拒吃鱼翅、万人签 } \\
\text { 名、冒雨救灾 }\end{array}$ \\
\hline
\end{tabular}

\section{3、影响小微企业众筹融资的因素}

\section{1 众筹融资缺乏立法保护, 法律法规监管缺失}

众筹作为舶来品, 在我国还没有相应的法律条款约束, 处在 “无门槛、无行业标准、无 监管” 的尴筴局面。我国法律不支持以股权、债券、利息、分红形式作为投资收益的融资方 
式，否则就被冠以非法集资之名, 我国众筹融资的运行面临较大的法律风险。

\section{2 众筹存在信用危机}

众筹是基于网络发展的融资新模式，投资人通过网页了解众筹项目，然后对其进行投资， 这一过程在一个虚拟空间进行，小微企业和众筹平台作为利益相关者，众筹平台能否公正审 核? 小微企业获得资金后如何运用？承诺的回报能否及时兑现？这些投资者均无法知晓，不 确定性风险引发严重的信任问题。

\section{3 众筹融资存在经营风险}

小微企业为解决资金问题，借助众筹进行集资，众筹的核心是融资项目，而项目的成功 与否又在于经营。首先，小微企业实力弱小，综合素质低下，管理能力欠缺，不能很好的推 行、管理项目, 就会导致经营的失败; 其次, 众筹平台的选择需 “对路”, 我国的众筹平台良 莠不齐，有的缺乏专业团队，专业管理，无形中就增大了经营风险。

\section{4 众筹项目知识产权得不到保护}

众筹项目讲求创意。小微企业为获取投资者的资金支持，在平台上充分展示项目的可行 性和新颖点。而此时这些项目都还是创意或是半成品, 没有来得及申请专利, 同时众筹平台 也无法确保项目的安全性使得小微企业的项目面临被剽窃的危机。再加上发起人产权保护意 识的缺失和知识产权保护力度的薄弱, 使得项目面临频频被抄袭的现象。

\section{4. 促进众筹融资模式良好发展的建议}

\section{1 健全法律法规, 完善监管体系}

目前，众筹在我国还缺乏相关法律的保护，存在较大的法律风险。为了有效降低风险， 使众筹模式健康发展。首先, 必须对现有的公司法、证券法、刑法等法律条文进行修改; 其 次, 建议各级政府尽早颁布适合众筹融资发展的法律法规, 明确众筹与非法集资方式的界限, 确保众筹的合法性，为股权众筹的中国化开辟新道路。最后，建立由地方政府主导的地方金 融监管体系框架和行业标准, 有效杜绝欺骗行为和跳票行为的发生。针对众筹融资建立信息 披露制度，对小微企业的相关信息，众筹项目的筹款期限、额度、预期回报率及众筹成功后 的信息进行充分持续的披露; 对投资者要形成参与标准, 明确参与、准入标准及退出机制, 对众多参与者进行篮选, 呈现过滤效应。

\section{2 引入保障机制, 降低信用风险}

信用风险的应对，是一个系统工程，需要参与方的配合。首先，小微企业要采用实名制 注册, 发起的项目要真实, 披露的信息准确可信, 项目信息及时更新, 出现问题及时解决。 其次, 作为项目的载体, 众筹平台要自律, 坚持中立立场, 对发起人的背景及诚信度进行严 格笁选和审核, 对资金的处理不设资金池。最后, 投资者要主动了解项目的情况, 避免受骗。 与此同时, 引入保障机制, 包括提示风险和信息披露, 根据市场需求, 及时调整产品供给, 提高产品的质量、制定平台标准和监督权限。采用信用累计或打分、资金第三方托管及分批 次划拨资金等方式 “加固” 双方信用，降低信用风险。

\section{3 规范平台发展}

国内众筹平台良莠不齐, 缺乏监管。我国应该学习美国的做法, 对想要融资的小微企业, 必须提供相关部门的信息文件; 众筹平台必须在相关部门登记注册, 并制定准入和豁免政策, 重点发展某一类众筹，不要眉毛胡子一把抓。对股权众筹的发展，可借鉴美国放宽对股权众 筹的监管, 以开放的心态, 降低门槛或不设门槛、鼓励创新的做法。引入专业团队, 以便为 小微企业进行专业指导，为投资者和参与者提供专业的服务知识，使其免受经营风险。 


\section{4 完善保护制度, 避免抄袭之风}

为避免抄袭之风，一方面，应该建议有关部门尽快制定并完善知识产权法和权益保护法， 在产品和创意展示之前, 进行登记或进行标注。另一方面, 应加强对小微企业的培训, 提升 专业素质和自我保护意识。主动申请专利来保护产品、创意, 然后再在平台上发布项目, 进 行筹资, 待筹资成功, 进入产品生产环节时再次完善。另外, 众筹平台可开发一些特定的企 业客户, 比如, 缺乏科研能力的企业, 将项目发起者的创意和技术与企业的资本和生产能力 有效结合起来。从而，确保项目和技术的安全。

\section{5 加大宣传力度, 普及众筹知识}

加强对众筹模式的宣传力度，普及众筹的概念，对投资者进行风险教育，与投资者签订 投资风险揭示书，促使大家密切关注各个栏目的动态和众筹项目的进程。政府部门应加大力 度宣传, 让参与者认识到众筹融资应用于小微企业融资的优势, 同时设立审查部门, 要求平 台定期汇报或不定期突击检查，来确保众筹的安全。

\section{5. 结束语}

小微企业融资难是当今社会面临的一个普遍问题。众筹融资模式作为一种基于互联网发 展的融资方式正在迅速成长, 为解决小微企业融资问题提供了新思路, 对小微企业的发展具 有积极的意义。但是我国众筹融资起步较晚, 缺少相应的法律, 如何做好其监管工作、保护 双方利益, 促进众筹融资在小微企业融资方面的应用仍需不断探索, 只有这样才能引导小微 企业 “众筹融资” 的可持续发展。

\section{References}

[1] Peng Hongchao ,Small and medium-sized enterprise financing research based on the raised platform,Modern Accounting,vol. 4, pp. 50-52, 2015.

[2] Zhang Wenhui.The development status and risk prevention of crowdfunding in China.,Foreign Economic Relations \& Trade,vol. 3, pp. 125-126+15, 2015.

[3] Steven Dresner,Crowd funding:An authoritative guide to Internet financing, China Renmin University Press,pp. 107-108, 2015. 